\title{
Cinemagmatic mayhem
}

\section{Dante's Peak}

A Roger Donaldson film

Universal Studios: 1997

\section{Jonathan Fink}

The first signs of an impending volcanic calamity can be hard to recognize. Dead trees and wildlife, cloudy tap water and unusual smells in the forest may all be explained by a variety of natural causes other than the stirrings of a magma chamber. Volcanologists who have to decide if such signals are benign or premonitory can face enormous personal and professional pressure. A false alarm can cost them their credibility and cost the local population millions of dollars in lost business; failure to predict a major eruption can result in tens of thousands of casualties. This dilemma lies at the heart of a spate of new films and television programmes.

As backdrops to melodrama, volcanic events are a scriptwriter's dream. Set in rugged terrain with dazzling scenery, most eruptions start slowly and ambiguously, building to a climax (or returning to calm) over periods of days, weeks, months or years. This uncertainty sets up potentially deadly conflicts between heroes (scientists and park rangers) who predict disasters, and villains (developers and politicians) who counsel a more cautious attitude. Chase-scene possibilities abound, with angry lava, pyroclastic flows, mudflows and landslides nipping at the heels or bumpers of fleeing, defenceless humans. Contrast all this potential with the more instantaneous, one-dimensional threats of earthquakes, asteroid impacts and tornadoes, and it is clear why they are becoming the movie moguls' disaster of choice.

Dante's Peak uses a volcano like Mount St Helens in the northwestern United States as a backdrop for a threatened town; US Geological Survey bosses and a greedy helicopter pilot as villains; a rogue British volcanologist as the dashing, misunderstood hero; and two children, a dog and a grandmother as victims in dire need of rescue. Disagreement among scientists about how to interpret geochemical and earthquake data delays the town's evacuation, guaranteeing a crisis at the film's core. The star, Pierce Brosnan, emulates his earlier James Bond role by outwitting the volcano at every turn while charming (and saving) the town's embattled mayor and her family.

Volcanologists got their first hint of this onrush of simmering celluloid last summer when a flurry of messages on an e-mail bulletin board called Volcano Listserv indicated that 1997 could be their profession's warholian 15 minutes of fame. Jack Lockwood, one of three consulting geologists for Dante's Peak, claimed it would have unprecedented scientific accuracy, educating its viewers while terrify-

\section{IMAGE UNAVAILABLE FOR COPYRIGHT REASONS}

Magma cum laude: Dante's Peak gets high marks from volcanologists.

ing them. Most of the volcanological community remained sceptical, especially when reports started circulating about another major production (Volcano, 20th Century Fox, scheduled for US release in May 1997) that has lava gushing out of the La Brea tar pits and spreading across downtown Los Angeles.

It may be that Dante's Peak will be enjoyed more by the experts than by the targeted teenage audience. There are dozens of anecdotal references to recent volcanological events, primarily through asides that will sound like idle chatter to most of the audience but will trigger vivid memories for regular volcanowatchers. Similarly, the subtle warnings that help Brosnan to sense an approaching disaster may be dismissed as implausible by people ignorant of volcanic processes, but will send shivers down the spines of those who have faced such situations themselves.

Not that the film is free from inaccuracies, however. The eruption is 'Hawaiified', with torrents of basaltic lava crashing through cabins and blocking escape routes. Although ancient basalts are found around many of the Cascade volcanoes, the simultaneous effusion of fluid magma streams and paroxysmal explosive eruptions has never been documented. Even more incredible is that Brosnan's four-wheel-drive vehicle spends several minutes traversing an active basalt flow without bursting into flames. (One of Lockwood's few complaints about the producers was their willingness to limit this lava-crossing episode to a more believable five seconds.) But even with these faults, the large audience and excellent computer effects should ensure that it enlightens more of the public about volcanic dangers than any previous film.

Dante's Peak, the television film Fire on the Mountain $(\mathrm{ABC})$ and the forthcoming Volcano might have been inspired by real events. The 1991 mega-eruption of Mount
Pinatubo in the Philippines, which was predicted by a team that included the seismologist David Harlow, one of the consultants on Dante's Peak, featured in the 1993 film In the Path of the Killer Volcano (Nova).

One of Dante's Peak's finest accomplishments, from both technical and educational standpoints, is its simulation of roiling ashflow clouds racing down the mountain's flanks. Few non-scientists are aware of these scorching blasts, and only a handful of people have survived encounters close enough to allow them to evaluate the accuracy of these special effects. Perhaps the best records of these and practically all other eruptive phenomena were made by the late cinematographers Maurice and Katia Krafft, a daring French couple who perished in 1991 while documenting pyroclastic flows at Mount Unzen in Japan. Although not trained as scientists, the Kraffts have protected more people from volcanic dangers than anyone else. Their films, including Understanding Volcanic Hazards and Reducing Volcanic Risk, have been shown to threatened villagers and townspeople around many of the world's most notorious volcanoes, and persuaded residents to prepare for possible future evacuation. Yet the Kraffts never took themselves as seriously as this year's 'cinemagmatists'. Maurice used to joke about building an asbestos and titanium kayak to slalom down active lava flows. It's a pity he never had the chance to do this as a cameo role in a Hollywood blockbuster.

Jonathan Fink is at Arizona State University, Tempe, Arizona 85287, USA. Readers interested in a free subscription to Volcano Listserv should use his email address, jon.fink@asu.edu. Understanding Volcanic Hazards and Reducing Volcanic Risk are available for $\$ 19.95$ each from NWIA, 3029 Spirit Lake Highway, Castle Rock, Washington 98611, USA. 